\title{
Editorial
}

\section{Management of Portal Hypertension - Digestive Diseases}

\author{
Antal Csepregi Peter Malfertheiner \\ Department of Gastroenterology, Hepatology, and Infectious Diseases, Otto von Guericke University, \\ Magdeburg, Germany
}

Portal hypertension and other complications of liver cirrhosis are still the leading causes of death in the developed world. The two major complications of liver cirrhosis are ascites formation and variceal hemorrhage. The development of fluid retention in the setting of cirrhosis is an important landmark in the natural history of chronic liver disease. Approximately $50 \%$ of patients with ascites die from liver cirrhosis within 2 years. The optimal management and appropriate treatment of patients with ascites require an optimized diagnostic process because approximately $15 \%$ of patients have a concomitant disease other than liver disease and in about $5 \%$ of cases 'mixed' ascites is diagnosed. Diuretics and antibiotics are established options for the treatment of fluid retention in liver cirrhosis. The issue 'tips or taps' to treat ascites remains open, and further studies are needed to determine outcomes in patients who received paracentesis or transjugular intrahepatic portosystemic shunt. Almost 90\% of patients with liver cirrhosis also develop varices, and about $30 \%$ of esophageal varices bleed. The first episode of variceal hemorrhage is estimated to carry a mortality rate of $30-50 \%$ in spite of important progress of interventional methods and availability of effective pharmacological treatment. This issue of Digestive Diseases provides an update and a progress report on the management of patients presenting with complications of portal hypertension. The authors have put great effort into presenting this complex issue in a complete and clear way. There are important novelties in the approach to the management of portal hypertension. The procedures and methods to achieve an efficient treatment of severe, potentially fatal complications of portal hypertension are complex. If interventional radiological and endoscopic as well as pharmacological treatment options fail, liver transplantation is the ultimate rescue to relieve portal hypertension, prevent variceal re-bleeding, ascites and encephalopathy by restoring liver function.

\begin{tabular}{|c|c|}
\hline KARGER & $\begin{array}{l}\text { (C) } 2005 \text { S. Karger AG, Basel } \\
0257-2753 / 05 / 0231-0005 \$ 22.00 / 0\end{array}$ \\
\hline $\begin{array}{l}\text { Fax +4161306 } 1234 \\
\text { E-Mail karger@karger.ch } \\
\text { www.karger.com }\end{array}$ & $\begin{array}{l}\text { Accessible online at: } \\
\text { www.karger.com/ddi }\end{array}$ \\
\hline
\end{tabular}

